\title{
El bandolerismo lusitano y la falta de tierras
}

\author{
Juan José Sayas abengochea *
}

1. El bandolerismo lusitano era un fenómeno que, sin ser exclusivo de Lusitania, alcanzó en ella cierta significación. Con su torpe actuación, Roma contribuyó a la acentuación de las causas determinantes del bandolerismo, aunque no hay duda de que el fenómeno se daba ya con anterioridad a la presencia romana. Los romanos difícilmente podian comprender el género de vida de los bandoleros. Ellos disponían de una organización política superior y mal podian valorar en su adecuado contexto social y económico las prácticas de bandolerismo. De ahí la denominación de latrones con la que se designa a los bandoleros y la dura represión contra los mismos que llevan a cabo los romanos '. Por el contrario, de parte de la población indígena había clara conciencia de que no practicaban una forma ilícita de vida, $y$ de hecho, los bandoleros se amparaban en la propia realidad social lusitana de la que procedian. Es, por otra parte, una forma de vida observable en muchos pueblos antiguos que pasaban por etapas económicas, sociales y culturales semejantes a la de los lusitanos. El fenómeno del bandolerismo y sus cau-

* Catedrático de Historia Antigua de la UNED.

1 Los romanos mantuvieron una actitud de desdén respecto de los pueblos indígenas con los que entraron en contacto y que vivian en situaciones económicas, sociales y culturales diferentes de las suyas. Una de las manifestaciones de ese desdén se aprecia en la atribución del epiteto de latrones a todos aquellos indigenas que les presentan una resistencia armada, pese a que los procedimientos empleados por Roma en su represión, no diferian mucho, ni cuantitativamente ni cualitativamente, de los utilizados por los indígenas. Un repaso rápido de las fuentes literarias e históricas permitirian apreciar la frecuencia con que se utiliza ese término en el sentido referido. En ocasiones el epíteto no se atribuye al conjunto de personas que practican el bandolerismo sino a la persona que dirige esas bandas. 
sas más hondas radicaban en la posesión de la tierra y en su distribución. El problema del bandolerismo era un problema eminentemente agrario ${ }^{2}$. $Y$ en esta línea de explicación se encuentra el análisis de algunos autores antiguos como Estrabón (III, 3, 5) o como Varrón (De agr. I, 16, 2) que aunque resalta las posibilidades económicas que brindaba la fertilidad de las tierras lusitanas, recomendaba, no obstante, no invertir en ellas, debido a la inseguridad y a la inestabilidad en la que se encontraban inmersas, todavía en su época, las tierras lusitanas.

Los autores antiguos ${ }^{3}$ dan sus propias visiones explicativas. A Estrabón, que reconstruye teórica y metodológicamente el proceso originario del bandolerismo, le parece lógico que hayan sido los lusitanos de las montañas los que hayan comenzado con el bandolerismo, porque habitaban un suelo casi improductivo, y poseían muy poco, razón por la cual apetecian los bienes de los demás. Este deseo y la adquisición de lo ajeno originará una serie de consecuencias encadenadas, porque los que sufren tales prácticas se ven atrapados en la misma dinámica social, ya que, al tratar de defenderse, tienen que cambiar el cultivo de la tierra por la milicia $y$, en esas circunstancias, la tierra deja de producir. De esta manera hubo gentes que perdieron sus propiedades y su relativo bienes-

2 Sin minimizar las diferencias cronológicas y las realidades propias de las que cada fenómeno de bandolerismo se nutre, vemos que hay un fondo común en el hecho del bandolerismo antiguo y en el bandolerismo social posterior. Se trata de un fenómeno social característico de sociedades agrícolas y pastoriles, sin trabajo y oprimidos por otros. En el caso del bandolerismo antiguo, originariamente puede tratarse, además, de sociedades tribales y de familias en las que era habitual el pillaje y el saqueo, que, al experimentar un proceso de diferenciación económica, sufrieron la automarginación de uno de sus sectores sociales que derivaria hacia el bandolerismo social. Ver E. J. Hobsbawm: Bandidos, trad. esp., Barcelona 1976, pp. 11 ss., y sobre este fenómeno S. L. Dyson: "Native Revolt, Pattern Patterns in the Roman Empire", A.N.R.W., II, 3, Berlin 1975, pp. 138 ss. El bandolerismo lusitano no to podemos considerar ni totalmente tribal o familiar, ni social en plenitud, pero lo cierto es que a la liegada de los romanos se daban ya realmente claras diferencias económicas en el seno de la comunidad lusitana, y que, con la imposición de sus esquemas económicos, Roma contribuyó a acentuarlas aún más.

${ }^{3}$ La idea de la relación que hay entre la diversidad de tierras y las diferentes formas de vida que adoptan sus habitantes, la ha podido tomar Estrabón de Posidonio. Ver H. Strasburger: "Posidonius on Problems of the Roman Empire", J.R.S., 1965, pp. 40-53; A. Momigliano: "Polybius and Posidonius", en Alien Wisdom, Cambridge 1975, pp. 22-49. Y lo mismo ocurre con Estrabón: P. PEDECH, «Strabon Historien": Studi Cataudella, Catania 1972, pp. 395-408. Ver también E. GABBA, "Storiografia greca e imperialismo romano", Riv. Stor. Ital., 86, 1974, pp. 625-642; P. DESIDERI, "L'interpretazione dell'imperio romano in Posidonio": Ist. Lomb. (rend. Lett.), 1972, pp. 481-493. En el caso de Apiano, éste lo ha podido tomar de Polibio. Ver al respecto S. SzadeCZKY-Kardocs: "Nouveau fragment de Polybe sur l'activité d'un proconsul romaine, distributeur de terres en Hispaniae", Oikumene, 1,1976 , pp. 99 ss. 
tar, y, por ende, esas tierras se poblaron de bandoleros. Esta situación afectó a los territorios situados entre el Tajo y los Artabros, que pertenecían a treinta "tribus". Dichos territorios sobresalian por su riqueza en productos agrarios, en ganado y minerales; pero la mayoria de sus habitantes abandonaron el cultivo de la tierra para dedicarse al pillaje, primero entre ellos y luego contra sus vecinos de la orilla meridional del Tajo. Por tanto, la falta de tierras, la pobreza de algunas de ellas y la indigencia de las gentes ha estado en la base del bandolerismo lusitano, y esto explica parte de la dinámica de los posteriores enfrentamientos con los romanos.

2. Las causas más hondas del fenómeno social del bandolerismo radicaba en la tierra y en su acaparamiento y distribución desigual que se traslucía consecuentemente en la existencia de dos capas sociales diferenciadas. Pero es preciso preguntarse cómo se había llegado a esta situación, no perdiendo de vista que este dualismo económico y social hundía sus raíces en épocas prerromanas, lo que ya de suyo agudiza todavía más el problema.

Se ha sugerido que en el fondo de este bandolerismo subyacía un conflicto social entre los dos sectores sociales y que, por lo tanto, el bandolerismo representaba una especie de movimiento de rebeldia del sector empobrecido ${ }^{4}$. Este tipo de consideraciones da una hipótesis explicativa, en cierto sentido aceptable, de la causa motriz del bandolerismo, pero no da, y ciertamente no lo pretende, una explicación de la génesis del dualismo económico y social que está en la base del bandolerismo.

2.1. Se ha ofrecido otro tipo de explicación. Se parte del supuesto de que se trata de un pueblo que en esos momentos mantiene vigente su organización gentilicia. En este sentido, se considera factible que, como ocurre en otros pueblos primitivos, para integrarse en una gentilidad, además de la consanguinidad fuese preciso superar algún tipo de pruebas. Si esta hipótesis de J. de Maluquer fuese factible, se tendría ya de esta manera un medio a través del cual pudiera haberse originado el

${ }^{4}$ Ver al respecto J. Caro Baroja: Los pueblos de España. Ensayo de etnología, Barcelona 1946, p. 201; A. GARCIA y BELLIDO: "Bandas y guerrillas en las luchas con Roma", Hispania, 21, 1945, pp. 68 ss. 
bandolerismo ${ }^{5}$. Ciertamente se indica que no hay huellas de que tales procedimientos de exigencias de pruebas específicas tuviesen lugar entre los lusitanos, pero, en este sentido, como en cierta manera adecuada a este tipo de suposición, da importancia a la frase de Diodoro ( $V, 34,6)$ respecto a que los lusitanos "cuando alcanzaban la edad viril se marchaban a las montañas".

Pero este pasaje de Diodoro que tiene su significación más importante, a nuestro parecer, como muestra de una concepción histórica coherente en cuanto explicación del bandolerismo, ofrece, por el contrario, pocas posibilidades cuando se quiere utilizar como testimonio de posibles pruebas que hubiera que superar para entrar en una gentilidad, basada ya de suyo sustancialmente en la consanguinidad. La frase, si no se extrapola del texto sino que se la incluye en el mismo, difumina todavía más la sugerente hipótesis explicativa de J. Maluquer: "existe una costumbre... sobre todo de los lusitanos, y es que, cuando llegan a la edad, aquellos que se encuentran en una situación apurada de recursos, pero sobresalen por el vigor de sus cuerpos y su arrojo armándose de valor y de armas, marchaban a las montañas" ${ }^{6}$. En este sentido, si se sigue en esta línea conceptual de suponer la posibilidad de que se diese la exigencia de pruebas para entrar en la gentilidad se llegaría a la conclusión de que la inclusión en la gentilidad no dependería exclusivamente en unas pruebas que hubieran de superarse sino, además, en función de la riqueza, por cuanto que al lado de "cuando llegan a la edad adulta", Diodoro especifica de un modo concreto y tasativo que son además: "aquellos que se encuentran en una situación apurada de recursos" los que derivan al bandolerismo. Además, mientras al "cuando llegan a la edad adulta", sobre todo si se le saca fuera del contexto, se le puede otorgar un carácter general, el resto de la frase: "aquellos que se encuentran en una situación apurada" es exclusivo y excluyente, $y$, por lo tanto, como norma general no son los ricos los que derivan al bandolerismo, sino los pobres. Así, pues, también en este supuesto palpita en el fondo una vez más ese dualismo económico y social entre ricos y pobres.

2.2. A este dualismo económico y social le cabe otro tipo de explicación de carácter étnico que se proyecta ciertamente en el oscuro problema del origen del pueblo lusitano?

${ }^{5}$ Ver al respecto las sugerencias de J. MaLuquen DE MOTES en Historia de España dirigida por R. Menéndez Pidal, I, 3, Madrid 1954, p. 153.

${ }^{6}$ Diodoro $(V, 34,6)$. Ver también A. Garcia y Bellido: "Bandas... op. cit., p. 19.

7 En la Ora Maritima de Avieno, frente a los Cempsi y los Sefes, se encuentran ocu- 
No hay duda que grupos indoeuropeos penetraron en el territorio lusitano, por más que se tenga incertidumbre respecto al tiempo en que pudo ocurrir y al espacio ocupado por los mismos y que encontraron y convivieron de una forma que con precisión no conocemos con unas comunidades preexistentes relativamente numerosas, que podemos considerar, para entendernos, como autóctonas. En el fondo de este conglomerado poblacional, había, pues, inicialmente un dualismo étnico. La población preexistente no desapareció. Algunos grupos pudieron pervivir en zonas relegadas, pero otros se aglutinaron, a través de un largo proceso, con los nuevos inmigrantes, que también ocuparon espacios vacíos de población. Por eso la explicación que arranca de una organización gentilicia general a todos no puede atribuirse, según nuestro modo de

pando parte del posterior territorio lusitano, los Dragani y los pernis Lucis. La última palabra se considera una equivocación del copista en lugar de Lusis, que de esta forma tendria una raíz de posible reigambre celta. También se prestaba atención al hecho de que el término lusitano tiene, en relación con otros pueblos que habitan otros territorios peninsulares, un conjunto de homonimias que se pensaba que no convenía minimizarlas: relación de los nombres lusitanos-lusones; la de un pueblo próximo a los lusones, Turmogoi y su semejanza con la ciudad lusitana de Turmogum. Incluso se sugeria el paso de los lusitanos a través del territorio de los Belli en razón a los topónimos actuales de Luzaga, Luzón, etc. Ver estos aspectos en A. MEndes CoRREA: Os povos primitivos da Lusitania, Porto 1924: $P$. BOSCH Gimpera: Etnologia de la Peninsula lbérica, Barcelona 1932, p. 600 ss.; ldem: "Lusitanos y Draganos", en Homenaje a Martins Sarmiento, 1933; S. Lambrino "Les Lusitaniens", Euphrosyne, 1, 1957, pp. 117-45; Idem, "Les celtes dans la Peninsule Iberique selon Avienus", Bull. Etud. Portug, 19, 1957, p. 24 SS.; F. Russel CORTEZ: "Contribución al estudio de la Protohistoria de los "Lusitani" (entre el Duero y el Tajo)", A.E.A. 28, pp. 90101. Las recientes excavaciones arqueológicas ponen de manifiesto que sobre el territorio lusitano confluyen las influencias de la Meseta y de la parte meridional de la Península. Cómo encajar los datos de la Arqueología y de la lingüistica resulta una tarea dificultosa. Pero es en el terreno del estudio de las lenguas primitivas de la Península donde la renovación, a partir de algunas inscripciones, ha sido más sensible, aunque no exenta de dificultades. Respecto a la lengua lusitana las opiniones están todavía divididas entre los que piensan que se dispone de indicios suficientes fonéticos y fonológicos para considerar que el lusitano es una lengua indoeuropea distinta del grupo céltico. (Así A. TOVAR: «Lenguas indoeuropeas: testimonios antiguos", Enciclopedia Lingüística Hispánica, Madrid 1960, pp. 101-126; Idem, "L'inscription du Cabeço dàs Fràguas et la langue des Lusitaniens", Etud. Celt., 11, 1964-5, pp. 237-268; Idem, "Etnia y lengua en la Galicia antigua: el problema del celtismo", en Estudos de cultura castrexa e de historia antigua de Galicia, Santiago de Compostela 1983, pp. 247-282) y los que aludiendo a la escasez de datos, a la existencia en territorio lusitano de topónimos en -briga de innegable raigambre céltica, y a la semejanza en el empleo de la onomástica personal en toda el área indoeuropea peninsular, piensan que se trata de una lengua de el área indoeuropea peninsular, piensan que se trata de una lengua de tipo céltico. (Asi J. UntermanN, "Personennamen als Sprachquelle im vorrömischen Hispanien" en /I Fachtagung für indogermanische und allgemeine Sprachwissenschaft, Innsbruck 1962, pp. 63-93; Idem, "Lusitanisch, Keltiberisch, Keltisch", en Studia Palaeohispanica. Actas del IV Coloquio sobre lenguas y culturas paleohispánicas, Victoriaco Vasconum, 1987, pp. 57-76.) Sobre el estado de la cuestión ver J. GorRoCHATEGUI, “En torno a la clasificación del lusitano: Studia Palaeohispanica... op. cit. pp. 77-91. 
entender, con exclusividad a los invasores sino que debe incluirse también a la población preexistente. Esto ha debido de ocurrir en una época temprana para que haya transcurrido un tiempo suficiente para conformarse como tal estructura social gentilicia unitaria. Y esta sociedad así configurada explotó para subsistir los territorios lusitanos, bien a través de la explotación colectiva bien de otro modo. Mas, desde el punto de vista de la riqueza del suelo, se tenía una variable importante. No todos los territorios lusitanos tenían las mismas posibilidades agropecuarias. Las zonas llanas de las cuencas del Tajo, Duero y Guadiana contrastaban con la escasa rentabilidad de las zonas de las montañas. Esto a la larga propició que hubiese comunidades con recursos abundantes y otras no. Pero, prescindiendo de las posibilidades agropecuarias concretas de cada zona, el caso es que los recursos obtenidos comenzaron a no ir masivamente en beneficio de todo el grupo social, como podría ocurrir en los casos de los pueblos en que las estructuras sociales indigenas se encontraban plenamente vigentes o tenían, como los Vacceos ${ }^{8}$ una especie, bastante enigmática, de colectivismo agrario, sino que aparecieron grandes diferencias en el disfrute de los mismos; mientras unos apenas alcanzaban los mínimos de subsistencia, otros acaparaban cuantiosas riquezas, dando lugar a grupos sociales empobrecidos. La producción agropecuaria lusitana, cualquiera que haya sido cuantitativamente, resultaba deficitaria por la apropiación desigual de las fuentes de riqueza. $Y$ esta desigualdad económica estaba originando la descomposición del sistema gentilicio en la suposición de que éste se hubiese configurado con carácter general. Siguiendo en esta línea de pensamiento, resulta que cuando las fuentes grecorromanas contemplan la realidad lusitana, ya estaban operando en ella con vigor las fuerzas desintegradoras de la estructura social indígena, por causa de las diferencias económicas anteriormente indicadas. En este contexto de diferenciación, social y económica se nutre la frugalidad general del lusitano, que toma "sólo una comida por día, que es sencilla y limpia» (Estrabón, III, 3, 6) y la que se predica de Viriato (Diodoro, 33, 7, 1). Esta frugalidad lusitana, sin duda alguna no apetecida, pero sí habitual y necesaria para el sector empobrecido del pueblo lusitano, no parece que deba generalizarse a los ricos, puesto que éstos no desaprovechan la ocasión de hacer ostentación de

${ }^{8}$ Sobre ese colectivismo agrario de los vacceos al que hace alusión Diodoro $(5,34$, 3) ver J. Caro Baroja (Los Pueblos... op. cit. p. 186), G. ThOMSON (Studies in Ancient Greek Society. reimp. Londres 1961, pp. 319 ss.). Sobre los aspectos económicos, sociales y culturales de los vacceos ver F. WATTENBERG, La región vaccea. Celtiberismo y romanización en la cuenca media del Duero, Madrid 1959. 
su riqueza y de su buena mesa, como ocurre con el suegro de Viriato en las bodas de éste.

2.3. Cabe también otro tipo de hipótesis explicativa. Se parte también de la consideración innegable de que grupos de indoeuropeos, de los que, como ya hemos señalado, no conocemos ni su proporción ni la dilación cronológica en su penetración ni los espacios concretos ocupados, han entrado en los posteriores territorios lusitanos. Cuando, posteriormente, contamos con datos literarios relativamente abundantes, éstos nos presentan el contraste entre personas que viven en la opulencia, como Astolpas, y grupos que encuentran en el bandolerismo su medio de vida.

Partiendo de esta realidad concreta, algunos se inclinan a proponer que esos invasores indoeuropeos constituyeron una aristocracia dominante, que se apoderó de las mejores tierras y empujó a la población preexistente hacia las zonas montañosas, condenándolas a vivir en condiciones precarias.

En esta hipótesis, la dualidad étnica invasores-población preexistente, estaría en la base de la diferenciación económica y social y daría lugar, consecuentemente, al bandolerismo del sector más empobrecido. Por el contrario, en la explicación anterior a ésta, la descomposición o transformación de la estructura social indígena sería una consecuencia de las diferencias económicas que surgieron dentro del cuerpo social. Luego, esas diferencias sociales y económicas, sobre todo en la posesión de la tierra, originarían y desarrollarian el bandolerismo.

Estamos, pues, ante una disyuntiva a la hora de explicar la diferenciación social, harto documentada por las fuentes antiguas en el seno de un pueblo, el lusitano, que, por otra parte, no deja de presentar una cierta unidad, o, por lo menos, aparece como tal para los romanos.

Desde el punto de vista de nuestro objeto, no es una de las cuestiones más interesantes tratar de determinar si en el momento en el que los lusitanos son conocidos por las fuentes grecorromanas se está operando un proceso de desintegración de una estructura social indígena relativamente uniforme, o bien los elementos divergentes económicos y sociales deben interpretarse como indicativos de un proceso de aglutinación étnica derivado de la integración de componentes poblacionales distintos. Mayor importancia tiene al respecto la constatación de que la falta 
de cohesión social lusitana deriva de una acusada diferencia económica, cuantitativa y cualitativa, entre los distintos elementos de su población.

3. El enrolamiento de lusitanos como tropas mercenarias fue una salida económica de aquellos sectores de la población que tenían como compañera a la miseria ${ }^{9}$. Antes incluso del enfrentamiento directo de los lusitanos con Roma, las fuentes históricas nos presentan a los lusitanos siviendo como mercenarios en los ejércitos de Anibal. Así cuando éste se encontró en el 218 a.C. en el Valle del Po, antes de entrar en combate, arengó de una manera especial a los lusitanos y celtiberos que servian en su ejército. Las palabras de Aníbal (T. Livio, 21, 43,8), dirigidas específicamente a ellos, sugieren que lusitanos y celtíberos constituían una parte importante del ejército que Anibal había llevado a Italia. Además, emerge con claridad a qué tipo de actividad se dedicaban esas gentes con anterioridad a su enrolamiento. Su ocupación era el pastoreo en los dilatados montes haciendo frente a continuos peligros y no sacando apenas ganancia.

Resulta evidente que los celtiberos y lusitanos enrolados pertenecían a aquella capa social empobrecida sin tierras y sin ganado propio, y dependiendo de las decisiones del grupo enriquecido de la sociedad ${ }^{10}$.

${ }^{9}$ Ya desde tiempos de Herodoto (7.165) se tienen testimonios de la utilización de mercenarios peninsulares al servicio de los cartagineses. Los mercenarios ibéricos (denominación que parece abarcar no sólo las zonas ibéricas, pues algún mercenario lleva nombre de raigambre indoeuropea) constituían un contingente importante en el ejército de los cartagineses durante las guerras sicilianas. Bien es verdad que mercenarios ibéricos se encuentran también militando en el ejército contrario. Para los mercenarios hispanos al servicio de Cartago ver A. GARCiA Y BELLIDO: "Factores que contribuyeron a la helenización de la España prerromana", BRAH, 104, 1943; P. BOSCH GIMPERA: "Les soldats ibériques agents d'héllenisation et de romanisation", en Melanges Carcopino, París 1966. Para la reiterada utilización posterior de mercenarios hispanos ver A. GARCIA Y BELLIDO, "Los auxiliares hispanos en los ejércitos romanos de ocupación (200-30 a.C.)", Emerita, 31,1963, pp. 213-226; A. BALIL: “Un factor difusor de la romanización: las tropas hispánicas al servicio de Roma (siglos ill-1 a.C.)", Emerita, 24, 1956, pp. 108-134.

${ }_{10}$ Parece que esa situación de miseria de un sector de la población es común a lusitanos y celtiberos. También respecto a estos últimos se señala la falta de tierras. Así, en el 181 a.C., parte de ellos, sobre todo los que tenían escasez de tierras, se retiraron a Complega y lucharon contra el procónsul Q. Fulvio Flanco (ApIano, Iber. 42-43). Y fue T. Sempronio Graco, sucesor del anterior, quien entregó tierras, especialmente a los indigentes reunidos en Complega (APIANO, Iber. 43-44). Más tarde, después de destruida Numancia, se repartieron tierras entre los vecinos (APIANo, Iber. 98). Por otro lado, aquellos celtibéricos que habían luchado del lado romano contra los lusitanos y que fueron establecidos en los alrededores de Colenda, viendo que sus tierras eran insuficientes, se dedicaron 
El enrolamiento con vistas a la obtención de una gran ganancia como la que les está prometiendo Aníbal debió de ser frecuente entre gentes que del riesgo permanente hacian un medio normal de vida.

Lusitanos y celtíberos gozaron, además, de justa fama como jinetes. Disponían de caballos dotados de cualidades adecuadas para moverse con desenvoltura y seguridad en las zonas montañosas, operación que en ese terreno no podian hacerlo con la misma habilidad los famosos caballos númidas de gran utilidad, por otra parte, para las llanuras. Anibal lo comprendió bien y supo sacar partido de ello utilizando ambas caballerías del modo adecuado en sus respectivos terrenos (T. Livio, 21,57,5).

Con la intención de asegurarse y controlar los territorios lusitanos que le proporcionaban cuantiosos contingentes a sus ejércitos hay que poner en relación, posiblemente, la localización en Lusitania, en el otoño del 210 a.C. de dos ejércitos cartagineses que estaban acampados en ella. Esta interpretación es más factible que la suposición de que los ejércitos púnicos alli estacionados llevaban a cabo una acción represiva.

La incorporación de grandes contingentes lusitanos a los ejércitos en lucha y la utilización de su territorio como teatro de operaciones militares se repetirá, en adelante, con bastante frecuencia ${ }^{11}$.

4. Otra salida a la situación de miseria era el pillaje y el bandolerismo. El pillaje de los pobres de la montaña contra los de la llanura, que como hemos indicado era producto de la pobreza y de la falta de tierra, se transformó cuando entró en juego Roma -elemento nuevo superpuesto y perturbador del proceder habitual indígena- en un movimiento mucho más amplio que alcanza no sólo a los pueblos próximos sino también a los aliados de Roma. Al deseo de rapiña se añadia la intuitiva e imprecisa decisión de enfrentarse a aquella potencia, y a los aliados peninsulares de ella, que está poniendo coto, en parte por exigencia de los compromisos contraídos con sus aliados, a las prácticas de saqueo

al bandolerismo. Frente a ellos, los romanos utilizaron la misma táctica que habian empleado frente a los lusitanos. El proconsul T. Didio (APIANO, Iber. 97-93) prometió entregarles las tierras de Colenda, pero, en lugar de hacerlo, los masacró (APIANo, Iber. 100).

${ }^{11}$ Asi durante la guerra civil (PLUTARCO, Sertorio, 10;12) apoyaron a los partidarios de Pompeyo (Bell. Hisp., 35) y proporcionaron jinetes y tropas auxiliares a Petreyo (Bell. Civ.., I, 38,3$)$. Incluso Bruto tuvo todavía en el 42 a.C. a 4.000 jinetes lusitanos. 
lusitanas habituales y normales desde el punto de vista de la mentalidad primitiva. Las tierras pobladas y fértiles del sur de la Península (Estrabón, III, 2,1 y III,2,4) constituirán un objetivo apetecido de las incursiones lusitanas. Ya en el 194 a.C., P. Cornelio Escipión Nasica interceptó y derrotó cerca de llipa (Alcalá del Río) a un grupo de lusitanos repartiendo entre sus soldados el botín que llevaban aquellos (T. Livio, 35.1. 3-12). También parece que en el 190 a.C. Emilio Paulo derrota a bandas armadas de lusitanos cerca de la ciudad de Lykon (T. Livio, 37.5.7). Los movimientos de lusitanos continuaron por tierras báticas hasta que el gobernador de la Ulterior, C. Atinio logró infringirles una gran derrota cerca de Hasta en el 186 a.C. (T. Livio, 39.7,6-7; 39.21,2-6).

Con lo que se considera como guerras lusitanas las proporciones de los hombres implicados en ellas, ya de por sí muy numerosas aumentaron considerablemente. Ya no se trataba de simples correrías de bandas saqueadoras. En el 155 a.C. los lusitanos atacaron. Al año siguiente el ejército del gobernador $L$. Calpurnio Pisón fue derrotado y sufrió grandes pérdidas a manos de los lusitanos que estaban mandados por Púnico ${ }^{12}$. Además, con la colaboración de los Vetones, llegó hasta el Océano, para dirigirse luego a la región de los blastofenicios, que eran aliados de Roma (Apiano, Iber. 56-57), y que estaban situados en la Andalucia oriental. Nada se conoce de este caudillo lusitano pero su nombre, Púnico, sugiere influencias culturales púnicas de los pueblos de la costa. Cuando Púnico murió las operaciones militares lusitanas las condujo Césaro. Por otro lado, en esos momentos los lusitanos situados más allá del Tajo, al mando de Cauceno atacaron a los Cunei, súbditos de Roma, y les tomaron su capital, Conistorgis. Luego, de acuerdo con la poco fiable información de Apiano (Iber. 57), pasaron el Estrecho y mientras unos asediaban la ciudad de Ocilis otros saqueaban otra parte de la costa africana. Luego el gobernador L. Mummius los derrotó (Apiano, lber., 57). El problema lusitano no tenía solución con las respuestas limitadas y puntuales con las que Roma respondía a los actos de provocación de los lusitanos. Operaciones de represalia y de castigo llevadas a efecto sobre el mismo territorio lusitano suponía una respuesta más contundente. El pretor de la Ulterior M. Atilio Serrano lo hace en territorio vetón en donde toma la ciudad de Oxthraca ${ }^{13}$. Su sucesor S. Sulpicio

12 Ver al respecto S. L. Dyson: «Native Revolt. op. cit., pp. 148-149. Ofrece la sugerencia de que por el nombre podría tratarse de un indigena aculturizado en las influencias púnicas de los grupos de la costa.

13 Para las acciones de saqueo lusitanas en la Ulterior, ver J. CHIC, «Consideraciones sobre las incursiones lusitanas en Andalucía", Gades, 5, 1980, pp. 15-25; L. A. GARCiA 
Galba, que al intentar taponar una invasión lusitana sobre el Betis medio sufrió una emboscada y tuvo que refugiarse en Carmona, preparó una operación combinada en el 150 a.C. con el gobernador de la Citerior L. Licinio Lúculo. Los lusitanos, acorralados, entablaron conversaciones de paz con Galba.

En las palabras que Apiano pone en boca de Galba, éste hace un análisis muy comprensivo de las causas por las que los lusitanos practicaban el bandidaje, hacian la guerra y no respetaban los pactos: "es la esterilidad de los campos y la pobreza lo que os obliga a ello". Luego, emplea el señuelo de la donación de buenas tierras para que depongan su actitud beligerante y de esa manera conducirlos engañosamente a la trampa mortal: "yo os daré, ya que lo necesitáis, tierras buenas, y os estableceré en una fértil campiña, dividiéndola en tres partes) (Apiano, lber. 58-60). El resultado fue una cruel masacre de lusitanos y la venta como esclavos de otros muchos. La historiografía moderna considera que la acción de Galba supuso una inflexión en el comportamiento romano frente a unas gentes culturalmente inferiores que ofrecieron conversaciones de paz. Se habla de un declive moral de las virtudes republicanas ${ }^{14}$. El hecho tuvo su eco en Roma y no fue ajeno a las confrontaciones políticas ${ }^{15}$. El tribuno de la plebe $L$. Scribonio Libo pidió la libertad de los lusitanos esclavizados y el procesamiento de Galba. Este asumió su propia defensa y con su celebrada elocuencia se vio libre de los cargos.

Pero al margen de las implicaciones morales, que posiblemente encubrian confrontaciones políticas, y que, por otro lado, perdian parte de su virtualidad por haber roto los propios lusitanos el pacto anterior, Galba

\footnotetext{
Moreno: "Infancia, juventud y primeras aventuras de Viriato", I Congreso de $\mathrm{H}^{2}$ Antigua peninsular, Santiago de Compostela 1988.

${ }^{14}$ Para E. S. Gruen: Roman Politics and the Criminal Courts, 149-78 BC, Cambridge, Mass. 1968, pp. 12-15, las acciones de Galba y el consiguiente debate supusieron un declive moral del gobierno republicano.

${ }^{15}$ Cuando Galba regresó a Roma se vio envuelto en un proceso. A sugerencias de $M$. Porcio Catón y de L. Cornelio Cethego, el tribuno de la plebe L. Scribonio Libo solicitó la condena de Galba y la libertad de los lusitanos esclavizados (F. DELLA CORTE: Catone censore, Florencia, 1969, pp. 119-21). Galba, uno de los oradores más afamados de su tiempo, asumió su propia defensa. Entre los que apoyaban su gestión se encontraba $Q$. Fulvio Nobilior (A. E. Astin: Cato the Censor, Oxford 1978, pp. 111-113). Considerando los que se han alineado a favor y en contra, se ha prestado atención al hecho de que entre los contrarios a Galba se alinean o representantes de la familia de los Cornelios, que tenían desde antiguo intereses en la Península, o personas que como Catón habian conducido hacia algún tiempo la política romana en Hispania. Por el contrario, Q. Fulvio Nobilior to había hecho en tiempos más cercanos a los acontecimientos de Galba.
} 
actuó en las guerras lusitanas de una manera realista. Los lusitanos habían violado los pactos lo que le permitía tomar de ellos las más duras represalias. Los saqueos desmoralizaban a los aliados de Roma y les causaban un gran quebranto económico. El problema, lusitano tenía un motivo económico y éste pasaba por una redistribución de la tierra que garantizara un asentamiento pacífico, que Roma ni tenía voluntad política de realizarlo ni estaba en condiciones de hacerlo.

En el 147 a.C. aquellos lusitanos que escaparon de las tropelías de Lúculo y Galba reiniciaron las razzias lusitanas en la Turdetania. Contra ellos se dirigió el pretor Cayo Vetilio. Mató a muchos y al resto los tuvo cercados. Ante la espectativa de morir de hambre los lusitanos entablaron conversaciones con Vetilio. Una vez más, Apiano (Iber. 61-63), que narra este acontecimiento, insiste en el anhelo lusitano por conseguir repartos de tierra. La marchacona insistencia en el mismo motivo señala a las claras que los lusitanos no veían otro camino para un cambio de actitud: "En vista de ello, remitieron una comisión con ramos de olivo a Vetilio, pidiéndole tierras en donde asentarse, comprometiéndose en adelante a mantenerse obedientes al pueblo romano. Vetilio prometió concederles tierras y estaba dispuesto a suscribir el pacto cuando Viriato... les recordó cuántas veces los romanos les habían atacado contra sus juramentos". Se ha considerado que las intenciones de Vetilio eran sinceras y que su deseo era de entregarles tierras. Como no se llevó a efecto, resulta difícil saber si se trataba de una promesa falaz o sincera. En cualquier caso, en el relato de Apiano la promesa no va acompañada de otro tipo de medidas pacificadoras y organizadoras del territorio tendentes a crear para los lusitanos un clima soportable en el que no sintiesen ni la lacerante miseria de algunas de sus gentes ni el pese amargo de una excesiva opresión romana. Engañosa o sincera, la promesa de Vetilio se parecia mucho a la de Galba. No resulta, por tanto, extraño que Viriato, que era uno de los que habian podido escapar de la masacre de Galba lograra persuadirlos para que no aceptaran el tratado, recordándoles el comportamiento romano de aquella ocasión.

La lucha se recrudeció ${ }^{16}$, y los lusitanos que habian encontrado en Viriato un gran caudillo llevaron a los romanos a situaciones militares

${ }^{16}$ Los acontecimientos de esta guerra pueden verse en H. H. SCHULLARD: The Romans in Spain 217 BC-AD 117, Londres 1939; H. SIMON: Roms Kriege in Spanien 154-133 v.Chr., Frankfurt 1962; O y S. da VeIGa Ferreira: $A$ vida dos Lusitanos no tempo de Viriato, Lisboa 1969. 
extremadamente comprometidas ${ }^{17}$. Pero el cansancio producido por esos años de ataques, persecuciones, huidas y luchas continuas forzó a Viriato a suscribir en el 141 a.C. un pacto cuando todavía se encontraba en óptima situación militar. Por ese pacto, el pueblo romano "se hacía amigo de Viriato y se aceptaba la posesión de las tierras adquiridas por los suyos" (Apiano Iber. 69). Una vez más emerge en Apiano la posesión de la tierra como el instrumento idóneo en la pacificación del territorio. Pero los romanos, no respeteron los pactos (Apiano, Iber. 70) prosiguieron la lucha hasta conseguir de forma innoble la muerte de Viriato.

Con la muerte de éste la capacidad militar de los lusitanos se debilitó, su espiritu combativo, no muy fuerte en los últimos tiempos, se resquebrajó todavía más y en adelante ya no constituyeron un peligro de proporciones tan serias como lo habían sido anteriormente. En esos momentos, los políticos y generales romanos creyeron llegado el momento de abandonar la fase de promesas incumplidas respecto al reparto de tierras para entrar en una fase de solución del problema del bandolerismo remediando las causas que lo provocaban. Se pasó, pues, a una etapa en la que se hicieron repartos efectivos de tierras, que por cierto, no alcanzaron a todos los lusitanos pobres. Las bandas de bandoleros que operaron tras la muerte de Viriato se van a ver beneficiadas de esta politica realista romana. Así Táutalo y su gente lusitana, a los que iba pisando los talones Cepión, se entregaron a éste en calidad de súbditos de Roma y Cepión "les concedió tierra suficiente para que la necesidad no les empujase al bandidaje" (Apiano, Iber. 72). Otra vez Apiano menciona la falta de tierra como causa del bandolerismo y considera que la entrega de la misma es el camino idóneo para acabar con el mismo. Diodoro $(33,1,3)$ completa esta información especificando que además de la concesión de tierras recibieron una ciudad en donde establecerse. Y esta política de concesión de tierras la practicó en el 138 a.C. el cónsul Junio Bruto con algunos de aquellos hombres que habian combatido anteriormente a las órdenes de Viriato, a los que "concedió tierras y una ciudad que recibió el nombre de Valencia" (T. Livio, Per. 55), ciudad cuya identificación es objeto de discusión ${ }^{18}$.

17 Sobre la figura de Viriato, magnificada por la historiografía alemana, ver A. SCHULTEN, Viriato, Porto 1927; G. GUNDEL: “Viriato, lusitano, caudillo en las luchas contra los romanos 147-139 a.C." trad. cast. en Caesaraugusta, 31-32, 1968; Idem: "Problems der römischen Kamptührung gegen Viriatus", en Legio VII Gemina, León 1970, pp. 111 ss.

${ }^{18}$ R. WiEgels: "Livio Per. 55 und die Gründung von Valentia", Chiron, 4,1974; C. CAllejo: La "Valentia" fundada por Junio Bruto, Cáceres 1981. 
Esta política y el firme proceso de romanización que llevaba consigo la creación y desarrollo de centros úrbanos, determinará la progresiva transformación de las estructuras sociales indígenas y un asentamiento mayor de la población en los centros urbanos. Este proceso es todavía bastante incompleto y afecta tan sólo a una parte de la población indigena lusitana. Al lado quedaban zonas geográficas marginales que serán el caldo de cultivo de los últimos baluartes del bandolerismo lusitano. Una de estas zonas, que era refugio de bandoleros, la constituirá el mons Herminius. En tiempos de César, después de que éste limpiara de bandidos Lusitania, intentó infructuosamente que los habitantes de la montaña se trasladasen a la llanura para que no se dedicaran al bandidaje cayendo desde el mons Herminius (Dion Casio, 37,52). Pero mientras esta política de asentamientos y de pacificación se van consiguiendo, como garantía de la misma, muchos de los centros urbanos ${ }^{19}$ que han emergido en Lusitania se configuran con cierto carácter militar.

19 Sobre el carácter militar de estos centros ver A. GARCIA Y BELLIDO: "Del carácter militar activo de las colonias romanas de la Lusitania y regiones inmediatas", Sociedade Portuguesa do Antropologia e Etnologia, Porto 1959, pp. 299-304. 